\title{
Mould and Process of an Injection Molding Rejuvenation Technique for Cable Insulation Failure*
}

\author{
XiaoJian Yang ${ }^{1,2, a}$ YongXiang Zhao ${ }^{1,3, b, * *}$ JunGuo Wang $^{1, \mathrm{c}}$, ZhiWei Liu ${ }^{1, \mathrm{~d}}$ \\ ${ }^{1}$ School of Mechanical Engineering, Southwest Jiaotong University, Chengdu, China \\ ${ }^{2}$ Shenhua Railway Wagon Transportation Company Ltd, Beijing, China \\ ${ }^{3}$ Technology and Equipment of Rail Transit Operation and Maintenance Key Laboratory of Sichuan Province, Chengdu, China
}

\begin{abstract}
Mould and process are developed for an injection molding rejuvenation technique of cable insulation failure. Disregard the traditional clue that repair does not expand original damage in size and space, a new rejuvenation technique, i.e. injection molding, is developed for restoring cable insulation failure. In this technique the uncertain damage in size and space was replaced by a standard eliminated size and space. In this way, an expanded original damage with certain size and space is firstly made around cable insulation failure section. But the damage situation was modified to a standard mode so that a mould technology can be well applied to filling the modified size and space. In addition, the bigger size and space is applied by mould for over-filling the modified size and space. Then a standard process should be constructed by the repair practices till the quality testing verifies that a successful rejuvenation is reached. Applied practice has verified the applicability and availability of the present technique.
\end{abstract}

\section{Introduction}

The reliable rejuvenation of cable insulation failure has important scientific and economic significance to ensure the safe operation of power production and transmission and electrical equipment, and hence it is a hot scientific and technological issue concerned by relevant departments.

The existing repair methods of cable insulation failure are mainly divided into two categories, one is the liquid injection chemical synthesis method [1-3], the other is the packing fixation method [4-5]. Liquid injection chemical synthesis method was used to repair water tree damage failure[6], and the repair fluid was also injected into the water tree defect between the cable insulation layer and the conductor, the repair solution reacted with the compound in the water tree defect to form a stable and insulating compound. Such rejuvenation may slow down the damage speed of water tree and prolong the service life of cable, but no production application case has been reported. The packing fixation method was applied to repair the local mechanical damage failure of cable insulation. The simplest was to fill the damaged area with self-adhesive insulation[4], and the complicated was that a cable clamp with heating ring was used to inject molten plastic sheet into the clamp hole to fill the damaged part of the cable[5].

Effective maintenance technology of cable insulation failure needs to have two basic characteristics, one is the production applicability, that is, the maintenance process method is complete and clear, and the corresponding repair quality is clear. The other is the acceptable repair effect. In fact, after the cable is repaired, it should reliably complete the power transmission task of specified withstand voltage level within the acceptable service time. Some important electrical projects such as modern electrified rail transit have strict requirements for the electrical conductivity of the cable under the protection of insulated sheath, the environmental safety of the insulation sheath material, and the mechanical strength capability[7].The two kinds of maintenance techniques mentioned above still have some difficulties in application to production. How to complete the implementation in production and obtain acceptable and recognized repair effect remains to be solved. Through repeated rejuvenation practice and changing the maintenance concept, a set of new technology for partial injection rejuvenation of cable insulation failure has been developed by us, and the standardized mold and process of the rejuvenation technique is introduced below.

\section{Mold Design and Manufacturing}

\subsection{Direct repair of injection mold}

The following factors need to be considered to design the removal space completely consistent with the standard cable.

(1) Match cable specification (diameter d)

(2) Match the space to be filled: The space includes the length $\mathrm{L} 1$, thickness $\mathrm{t} 1$, nominal diameter $(\mathrm{d}+\mathrm{t} 1)$ of single layer cable, length L2, thickness $\mathrm{t}$ 2, and nominal diameter

\footnotetext{
a xiaojian_yang@163.com ${ }^{* b} 1760465099 @ q q . c o m{ }^{c}$ jg_wang2000@163.com d 779894575@qq.com
} 
$(\mathrm{d}+2 \mathrm{t} 1+\mathrm{t} 2)$ of the sheath layer.

(3) The mold includes the structure of feeding and connecting with the injection molding machine to realize the automatic opening and closing action of injection molding, as well as the structure of creating the injection environment and connecting with the mold temperature machine.

Taking the design and development of direct injection mold for repairing the middle section of the flexible cable with EPDM insulation/chlorosulfonated polyethylene sheath as an example, the specific implementation method is described.

(1) According to local removal rule of double-layer cable failure with "internal short and long length", each specification has internal and external layer local removal. There are four schemes as shown in Figure 1.

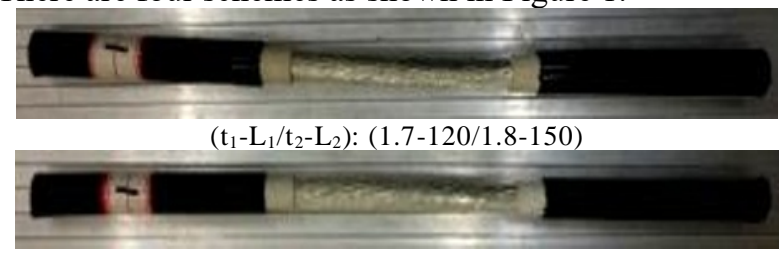

$\left(\mathrm{t}_{1}-\mathrm{L}_{1} / \mathrm{t}_{2}-\mathrm{L}_{2}\right):(1.4-120 / 1.4-150)$

a.Cable with cross section of $120 \mathrm{~mm}^{2}$

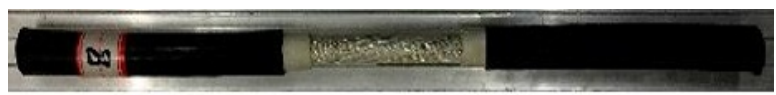

$\left(\mathrm{t}_{1}-\mathrm{L}_{1} / \mathrm{t}_{2}-\mathrm{L}_{2}\right):(1.7-80 / 1.8-110)$

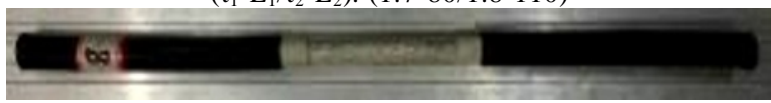

$\left(\mathrm{t}_{1}-\mathrm{L}_{1} / \mathrm{t}_{2}-\mathrm{L}_{2}\right):(1.4-80 / 1.4-110)$

b. Cable with cross section of $70 \mathrm{~mm}^{2}$

Fig1. Specimens of the cable elimated local insolutions and sheaths in standard geometries

(2) According to the principle that the injection space of the mold completely matches the space to be repaired, the space structure of the injection mold is designed and manufactured.
(3) To realize the feeding, automatic opening and closing of the mold and creation of the injection temperature environment, structure of the mold, connection with the injection molding machine and mold temperature machine are designed.

Figure 2 shows the photos of four kinds of direct repair molds used for repairing the inner and outer layers of two kinds of cables, and Table 1 shows the local removal parameters for cable samples with cross sections equal to $120 \mathrm{~mm}^{2}$ and $70 \mathrm{~mm}^{2}$, respectively.

\subsection{Indirect repair of injection mold}

The goal of indirect repair mold design and manufacturing is to make a repair film which fills the cable space. Therefore, the geometry of the repair film determines the design and manufacture of the indirect repair mold. Here the specific implementation method is as follows.

\subsubsection{Preparation space of repair membrane}

Considering the follow-up process, it is beneficial to fill the cable removal space reliably after hot pressing. If the repair membrane which is exactly the same as the filling space is used, the thermal bonding alone may affect the repair effect. So it is suggested that the volume match, the width equal to the perimeter of the space to be filled, the thickness is slightly thick and the length is slightly short. The injection space length a1, width w1, height b1 of the inner repair film mold should meet the following conditions.

$$
\left\{\begin{array}{l}
\boldsymbol{a}_{1}<\boldsymbol{L}_{1} \\
\boldsymbol{w}_{1}=\pi\left(d+\boldsymbol{t}_{1}\right) \\
\boldsymbol{b}_{1}=\boldsymbol{L}_{1} \boldsymbol{t}_{1} / \boldsymbol{a}_{1}
\end{array}\right.
$$

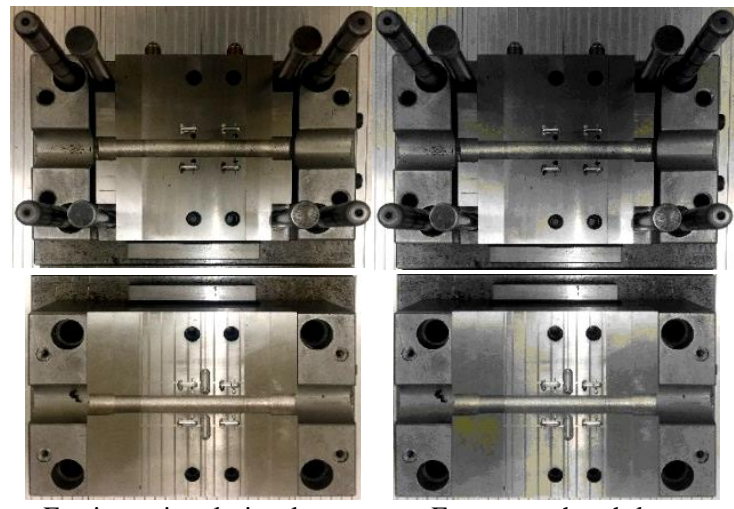

For inner insulation layer a.Cable with cross section of $120 \mathrm{~mm}^{2}$ 


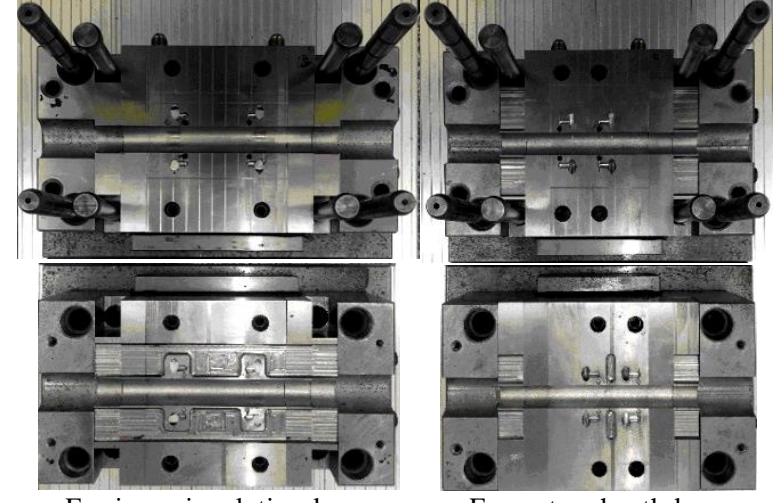

For inner insulation layer

b. Cable with cross section of $70 \mathrm{~mm}^{2}$

Fig2. Molds for directly rejuvenating insolutions and sheaths with standard injection platic geometries matching the cable elimated spaces

The injection space length a2, width w2, height b2 of the outer repair film mold also should meet the following conditions.

$$
\left\{\begin{array}{l}
\boldsymbol{a}_{2}<\boldsymbol{L}_{2} \\
\boldsymbol{w}_{2}=\pi\left(\boldsymbol{d}+2 \boldsymbol{t}_{1}+\boldsymbol{t}_{2}\right) \\
\boldsymbol{b}_{2}=\boldsymbol{L}_{2} \boldsymbol{t}_{2} / \boldsymbol{a}_{2}
\end{array}\right.
$$

(2) Similarly, in addition to the filling structure, the design and manufacturing of indirect repair mold need to consider the structure of connecting with the injection molding machine to realize the feeding, automatic opening and closing of the mold, and temperature environment control with the mold temperature machine. Table 2 shows the geometric dimension parameters of injection space of cable repair film mold developed. Figures 3 and 4 show the photos of repair film mold and the prepared injection film object.
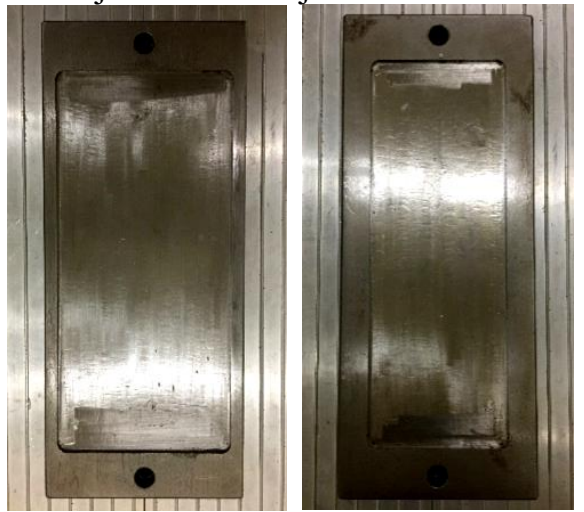

Fig3. Molds for machining injection plastic films with standard geometries to indirectly rejuvenate the cable insolutions and sheaths

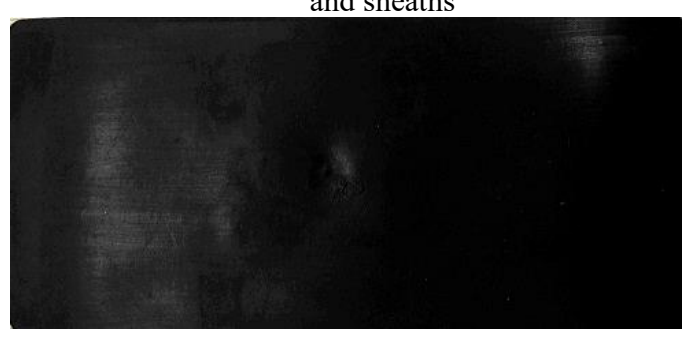

a. $\quad 140 \times 63.46(\times 1.93)$

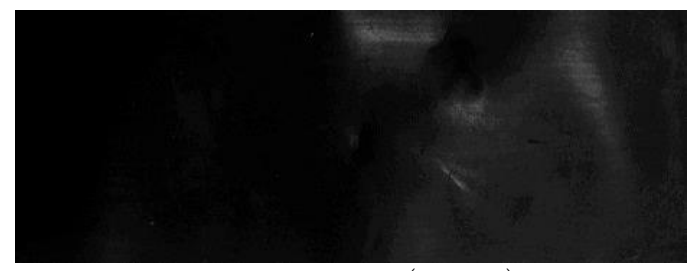

b. $100 \times 63.46(\times 1.98)$

Fig4. Injection plastic films for indirectly rejuvenating cable insolutions and sheaths in standard geometries

\section{Injection Molding Process}

\subsection{Mold temperature machine matching}

The environment of injection molding is guaranteed by mold temperature machine. Cable insulation/ sheath material is generally rubber or PVC polymer mixture material, its effective working temperature is equal to $-40^{\circ} \mathrm{C}$ $\sim 120{ }^{\circ} \mathrm{C}$, and the solution temperature or softening temperature is generally $140 \sim 200{ }^{\circ} \mathrm{C}$. Therefore, it is necessary to select a mold temperature machine with good stability control ability at $0 \sim 260^{\circ} \mathrm{C}$.

\subsection{Mold temperature machine matching}

The injection molding process, such as feeding, mold closing and pressure maintaining, mold withdrawal and cooling, is completed by the linkage of injection molding machine. Generally, it is necessary to do the three aspects. Firstly, the conveying capacity of the injection molding machine is not lower than that of the filling space, the feeding amount of the injection molding machine each time is greater than the maximum removal amount of insulating materials in inner/outer layers of the cable to be repaired. The second is that the temperature control range, feeding, mold closing/holding, and mold cooling of are accurate and reliable. The third is that the connection function between the injection molding machine and the mold are reliable.

\subsection{Direct and indirect injection repair process}

Through the research of standardized direct injection molding process, the local injection repair work of cable 
insulation failure can be implemented. Figure 5 displays main injection technological process of directly rejuvenating cable insolution layer. Through the development of standardized indirect injection molding
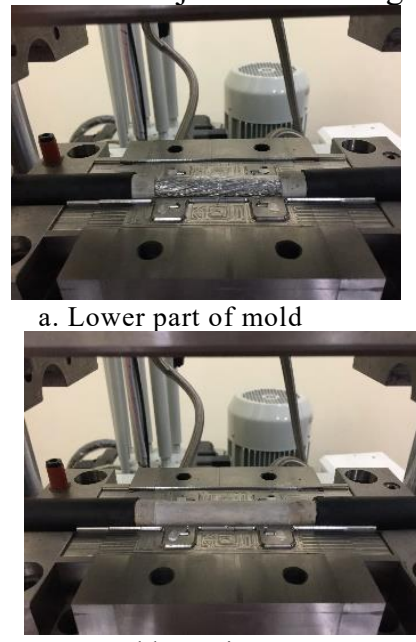

c. Mold opening state

Fig5. Main injection technological process of directly rejuvenating cable insolution layer

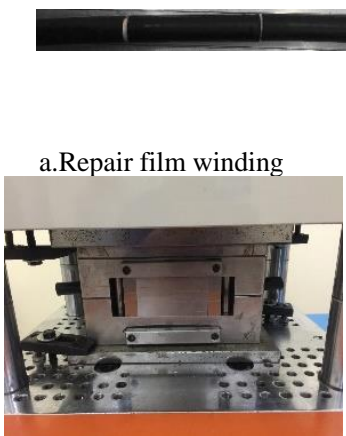

c. Extrusion mold closing process, the indirect injection repair work can be implemented. The main process includes injection molding and extrusion, which is shown in Figure 6.

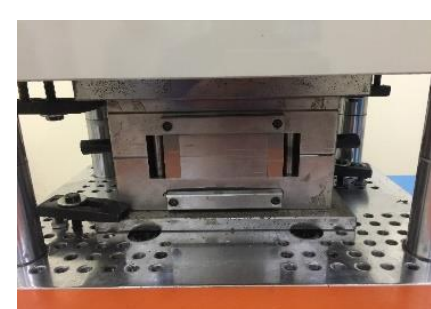

b. Mold up and down closed

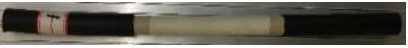

d. Cable after insulation repai

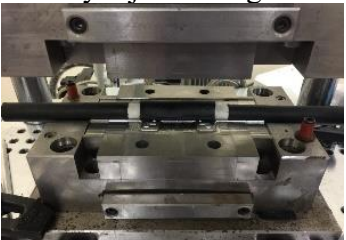

b. Lower part of mold

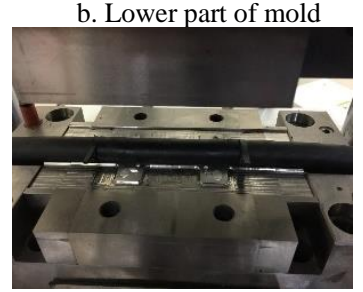

d. Mold opening/sheath repai

Fig6. Main extrosive forming technological process of indirectly rejuvenating cable sheath layer with standard injection plastic film

Table1. Local removal parameters for cable samples with different cross sections area

\begin{tabular}{|c|c|c|c|c|c|c|c|}
\hline \multirow{2}{*}{$\begin{array}{c}\text { Cross section area } \\
\mathrm{A}\left(\mathrm{mm}^{2}\right)\end{array}$} & \multirow{2}{*}{$\begin{array}{l}\text { Core diameter } \\
\qquad \mathrm{d}(\mathrm{mm})\end{array}$} & \multirow{2}{*}{$\begin{array}{c}\text { Inner thickness } \\
t_{1}(\mathrm{~mm})\end{array}$} & \multirow{2}{*}{$\begin{array}{c}\text { Outer thickness } \\
\mathrm{t}_{2}(\mathrm{~mm})\end{array}$} & \multicolumn{2}{|c|}{ Notch length I } & \multicolumn{2}{|c|}{ Notch length II } \\
\hline & & & & $\mathrm{L}_{1}(\mathrm{~mm})$ & $\mathrm{L}_{2}(\mathrm{~mm})$ & $\mathrm{L}_{1}(\mathrm{~mm})$ & $\mathrm{L}_{2}(\mathrm{~mm})$ \\
\hline 120 & 15 & 1.7 & 1.8 & 120 & 150 & 80 & 110 \\
\hline 70 & 14 & 1.4 & 1.4 & 120 & 150 & 80 & 110 \\
\hline
\end{tabular}

Table2. Geometric parameters of standardized local removal and indirect repair film for cable failure

\begin{tabular}{|c|c|c|c|c|c|c|c|}
\hline \multicolumn{5}{|c|}{ Parameters of cable with repair } & \multicolumn{3}{|c|}{ Indirect repair of inner cavity of mold } \\
\hline $\begin{array}{c}\text { Cross section area } \\
\qquad \mathrm{A}\left(\mathrm{mm}^{2}\right)\end{array}$ & $\begin{array}{l}\text { Core diamete } \\
\mathrm{d}(\mathrm{mm})\end{array}$ & $\begin{array}{c}\text { Inner } \\
\text { thickness } \\
\mathrm{t}_{1}(\mathrm{~mm})\end{array}$ & $\begin{array}{c}\text { Outer } \\
\text { thickness } \\
\mathrm{t}_{2}(\mathrm{~mm})\end{array}$ & $\begin{array}{c}\text { Remove the } \\
\text { length } \\
\mathrm{L}_{2}(\mathrm{~mm})\end{array}$ & $\begin{array}{l}\text { Length } \\
\mathrm{a}_{2}(\mathrm{~mm})\end{array}$ & Width $\mathrm{w}_{2}(\mathrm{~mm})$ & $\begin{array}{c}\text { thickness } \\
\mathrm{b}_{2}(\mathrm{~mm})\end{array}$ \\
\hline \multirow{2}{*}{120} & \multirow{2}{*}{15} & \multirow{2}{*}{1.7} & \multirow{2}{*}{1.8} & 150 & 140 & 63.46 & 1.93 \\
\hline & & & & 110 & 100 & 63.46 & 1.98 \\
\hline \multirow{2}{*}{70} & \multirow{2}{*}{14} & \multirow{2}{*}{1.4} & \multirow{2}{*}{1.4} & 150 & 140 & 57.18 & 1.5 \\
\hline & & & & 110 & 100 & 57.18 & 1.54 \\
\hline
\end{tabular}




\section{Conclusions}

(1) Breaking through the conventional maintenance idea that the repair process does not expand the product damage is the basis for realizing the standardized repair of cable insulation/sheath products.

(2) Standardized mold and process technology of local injection rejuvenation technique of cable insulation failure is based on matching cable standardized removal space, combined with injection molding machine and mold temperature machine, which can match the needs of repair material injection molding process and achieve the best cable repair effect.

(3) Rejuvenation process of local injection molding of cable insulation failures includes direct and indirect injection repair. The former includes direct repair mold and injection molding process, the latter designs and manufactures repair film preparation mold which matches the repair space. The local injection rejuvenation technique of cable insulation failure is expected to be applied in production.

\section{Acknowledgment}

*The present research is supported by Shenhua Group Science and technology innovation project (hcky-201613). ** Corresponding author

\section{References}

1. P. Nannery, J. Tarpey, J. Lacenere, J. Meyer and G. Bertini, "Extending the service life of $15 \mathrm{kV}$ polyethylene URD cable using silicone liquid," IEEE Trans., on Power Delivery, vol. 4, pp. 1991-1996, April 2002.

2. X. Zhu, "The repair liquid injection technology of XLPE cable for repairing water tree," High Voltage Engineering, vol. 30, pp. 16-17, May 2004.

3. A. Thomas and T. Saha, "A new dielectric response model for water tree degraded XLPE insulation-Part A: model development with small sample verification," IEEE Trans., on Dielectrics and Electrical Insulation, vol. 15, pp. 1131-1143, April 2008.

4. J. Wang and L. Ma. A cold sticky rubber band for rejuvenation mining cable. China: CN2272624Y, 1996.

5. H. Teng. A equipment for rejuvenation damaged insulation of cable with supporting. China: CN201620322979, 2016.

6. S. Boggs, J. Densley and J. Kuang, "Mechanism for impulse conversion of water trees to electrical trees in XLPE," IEEE Trans., on Power Delivery, vol. 13, pp. 310-315, February 1998.

7. CRRC Zhuzhou Institute Co., Ltd, "Specification for cables on board rolling stock-Part 1: Standard wall insulation cables up to AC $3 \mathrm{kV}$," Zhuzhou,China, 2010 . 